\title{
THE ROLE OF MAGMATIC HEAT SOURCES IN THE FORMATION OF REGIONAL AND CONTACT METAMORPHIC AREAS IN WEST SANGILEN (TUVA, RUSSIA)
}

\author{
O. P. Polyansky¹, S. A. Kargopolov1, 2, A. E. Izokh'1, 2, A. N. Semenov ${ }^{1}$, \\ A. V. Babichev ${ }^{1}$, A. N. Vasilevsky ${ }^{3,2}$ \\ 1 V.S. Sobolev Institute of Geology and Mineralogy, Siberian Branch of RAS, Novosibirsk, Russia \\ 2 Novosibirsk State University, Novosibirsk, Russia \\ ${ }^{3}$ A.A. Trofimuk Institute of Petroleum Geology and Geophysics, Siberian Branch of RAS, Novosibirsk, Russia
}

\begin{abstract}
The tectonomagmatic evolution of the Sangilen massif has been described in detail in numerous publications, but little attention was given to heat sources related to the HT/LP metamorphism. Modeling of the magma transport to the upper-crust levels in West Sangilen shows that the NT/LP metamorphism is related to gabbromonodiorite intrusions. This article is focused on the thermo-mechanical modeling of melting and lifting of melts in the crust, taking into account the density interfaces. The model of the Erzin granitoid massif shows that in case of fractional melting, the magma ascent mechanism is fundamentally different, as opposed to diapir upwelling - percolation take place along a magmatic channel or a system of channels. An estimated rate of diapiric rise in the crust amounts to $0.8 \mathrm{~cm} / \mathrm{yr}$, which is more than an order of magnitude lower than the rate of melt migration in case of fractional melting ( $25 \mathrm{~cm} / \mathrm{yr}$ ). In our models, a metamorphic thermal 'anticline' develops in stages that differ, probably, due to the modes of crust melting: batch melting occurs at the first stage, and fractional melting takes place at the second stage. It is probable that the change of melting modes from melting conditions in a 'closed' system to fractional melting conditions in 'open' systems is determined by tectonic factors. For the Sangilen massif, we have estimated the degrees of melting in the granulite, granite, and sedimentary-metamorphic layers of the crust $(6,15$, and 5 vol. $\%$, respectively)
\end{abstract}

Key words: heat transfer; modeling; contact metamorphism; Sangilen; melting; melt; zoning; crust; magmatic chamber

For citation: Polyansky O.P., Kargopolov S.A., Izokh A.E., Semenov A.N., Babichev A.V., Vasilevsky A.N., 2019. The role of magmatic heat sources in the formation of regional and contact metamorphic areas in West Sangilen (Tuva, Russia). Geodynamics \& Tectonophysics 10 (2), 309-323. doi:10.5800/GT-2019-10-2-0416. 


\title{
РОЛЬ МАГМАТИЧЕСКИХ ИСТОЧНИКОВ ТЕПЛА ПРИ ФОРМИРОВАНИИ РЕГИОНАЛЬНОГО И КОНТАКТОВЫХ МЕТАМОРФИЧЕСКИХ АРЕАЛОВ ЗАПАДНОГО САНГИЛЕНА (ТУВА)
}

\author{
О. П. Полянский ${ }^{1}$, С. А. Каргополов ${ }^{1,2}$, А. Э. Изох ${ }^{1,2}$, А. Н. Семенов ${ }^{1}$, \\ А. В. Бабичев ${ }^{1}$, А. Н. Василевский ${ }^{3,2}$ \\ ${ }^{1}$ Институт геологии и минералогии им. В.С. Соболева СО РАН, Новосибирск, Россия \\ ${ }^{2}$ Новосибирский национальный исследовательский государственный университет, \\ Новосибирск, Россия \\ ${ }^{3}$ Институт нефтегазовой геологии и геофизики им. А.А. Трофимука СО РАН, Новосибирск, Россия
}

\begin{abstract}
Аннотация: Тектономагматическая эволюция Сангиленского массива детально охарактеризована в многочисленных публикациях, в то время как источникам тепла при метаморфизме HT/LP-типа уделялось мало внимания. Моделирование процессов транспорта магм на верхнекоровые уровни является актуальным, так как для Западного Сангилена устанавливается связь метаморфизма HT/LP-типа с габбро-монцодиоритовыми интрузиями. Статья посвящена результатам термомеханического моделирования порционного режима плавления и подъема расплавов в коре с наличием плотностных границ. Объект моделирования - Эрзинский гранитоидный массив. Показано, что в отличие от диапирового всплывания механизм подъема магмы при фракционном плавлении оказывается принципиально иным - в форме просачивания по магматическому каналу (системе каналов). Оценено, что скорости подъема диапиров в земной коре (0.8 см/год) более чем на порядок ниже скорости миграции расплава при фракционном плавлении, которая составляет 25 см/год. Показано, что этапы развития метаморфической термальной «антиклинали» могли быть обусловлены разным режимом плавления материала коры: на первом этапе - порционного типа, на втором - фракционного. Смена режимов плавления от условий плавления в «закрытой» системе к условиям фракционного плавления в «открытых» системах, вероятно, определялась тектоническими факторами. Сделаны оценки степени плавления в гранулитовом (6 об. \%), гранитном (15 об. \%) и осадочно-метаморфическом (5 об. \%) слое коры Сангиленского массива.
\end{abstract}

Ключевые слова: теплоперенос; моделирование; контактовый метаморфизм; Сангилен; плавление; расплав; зональность; кора; магматическая камера

\section{1. ВВЕДЕНИЕ}

Метаморфические комплексы и пояса HT/LPметаморфизма широко распространены в орогенических поясах. Выделение и характеристика HT/LPметаморфизма являются особенно актуальными в связи с проблемами аномальных тепловых потоков в коре и геодинамической типизации обстановок его проявления. Изучение HT/LP-метаморфизма позволяет детализировать последовательность эндогенных событий и, в том числе, P-T-t-d эволюцию коры. Вместе с тем имеются до конца не исследованные вопросы, связанные с изучением поясов HT/LP-метаморфизма: какова природа тепловых источников, каким образом работают механизмы теплопереноса и транспорта магмы/расплава, всегда ли обоснована генетическая связь с интрузивными комплексами? Имеются примеры приповерхностных проявлений контактового метаморфизма, где эта связь достоверно установлена [Sokol et al., 2019]. Сложнее дело обстоит в случае «скрытых» интрузий, признаками которых являются высокотемпературные зонально-метаморфические комплексы.
Главным вопросом в проблеме формирования HT/LP-метаморфизма являются аномальные тепловые потоки на уровне средней и верхней коры со значениями метаморфических градиентов более $75{ }^{\circ} \mathrm{C}$ /кбар [Brown, 2006, 2007; Pattison et al., 2003; Kelsey, Hand, 2015]. Одним из наиболее ярких примеров проявления HT/LP метаморфизма являются метаморфические зональные комплексы нагорья Сангилен Тувино-Монгольского массива.

Целью настоящей статьи является построение модели плавления и транспорта магмы в коре Сангиленского блока при формировании крупных контактово-региональных метаморфических ареалов и обоснование механизма генерации аномального (более $75{ }^{\circ} \mathrm{C} /$ кбар) теплового потока при формировании комплексов HT/LP типа.

В качестве объекта для моделирования процессов плавления выбран Эрзинский гранитоидный массив. Последний приурочен к Эрзинской тектонической зоне и относится к баянкольской габброгранитной серии.

Эрзинский массив расположен в междуречье рек Эрзин и Нарын (рис. 1, a). В составе массива 


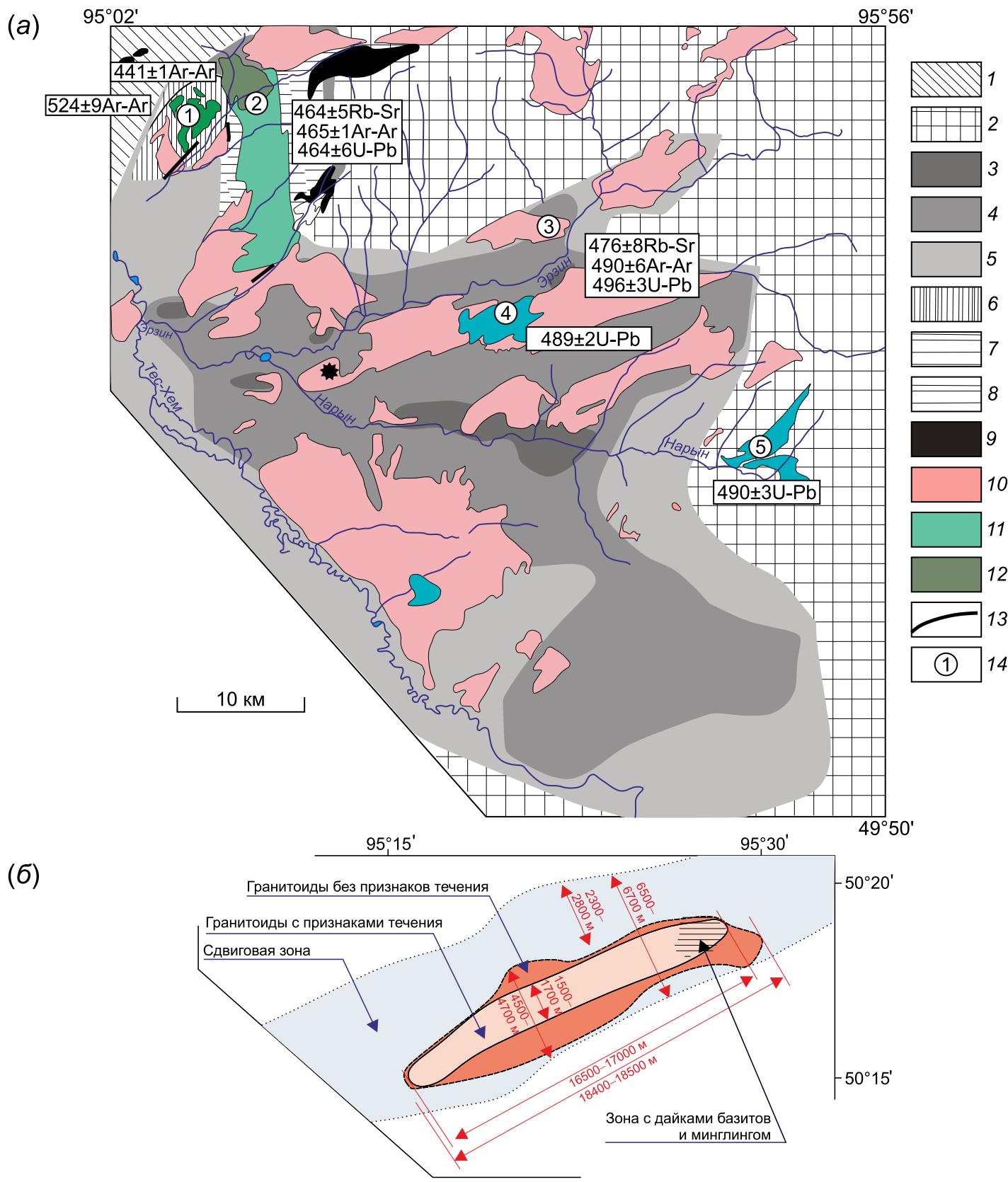

Рис. 1. (a) - схема распространения и этапы высокоградиентного (HT/LP) метаморфизма Западного Сангилена (ЮгоВосточная Тува) (по данным [Izokh et al., 2001], с изменениями) ; (б) - форма, линейные характеристики Нижнеэрзинского гранитного массива и положение минглинг-структур на участке «Стрелка» (по данным [Vladimirov et al., 2017; Polyansky et al., 2017]).

1 - метавулканиты кускунугского бассейна; 2 - ореол распространения барровианского (кианит-сланцевого) метаморфизма М1, перекрытый к востоку карбонатным чехлом сангиленской серии; 3-8 - метаморфизм HT/LP-типа: 3-5 - метаморфические образования с возрастом 490 млн лет: 3 - гиперстеновая зона, 4 - силлиманитовая зона, 5 - андалузитовая зона; 6 - двупироксеновые и силлиманит-калишпатовые роговики, связанные с Правотарлашкинским массивом (524 млн лет); 7-8 - метаморфические образования с возрастом 465 млн лет: 7 - гиперстеновая зона, 8 - силлиманитовая зона; 9 - гипербазиты; 10 - граниты (нерасчлененные); 11 - диориты и монцодиориты; 12 - дифференцированные габброиды; 13 - разлом; 14 - интрузивы габброидов. Звездочкой показано местоположение участка Нижнеэрзинского гранитного массива, увеличенного на рис. (б).

Fig. 1. (a) - distribution and stages of high-gradient (HT/LP) metamorphism of West Sangilen (Southeastern Tuva, Russia) (according to [Izokh et al., 2001], with modifications); (б) - shape and linear characteristics of the Nizhny Erzinsky granite massif, and the positions of mingling structures (Strelka site) (according to [Vladimirov et al., 2017; Polyansky et al., 2017]).

1 - metavolcanites of the Kuskunug basin; 2 - area of the Barrovian (kyanite-shale) metamorphism M1 overlain to the east by the carbon nappe of the Sangilen series; 3-8 - HT/LP metamorphism: 3-5 - metamorphic formations (490 Ma): 3 - hypersthene zone, 4 - sillimanite zone, 5 - andalusite zone; 6 - bipyroxene and sillimanite-kalispar hornfels related to the Pravotarlashkin massif (524 Ma); 7-8 - metamorphic formations (465 Ma): 7 - hypersthene zone; 8 - sillimanite zone; 9 - hyperbasites; 10 - granites (undifferentiated); 11 - diorites and monzodiorites; 12 - differentiated gabbroids; 13 - fault; 14 - gabbroid intrusives. The asterisk marks the location of the Nizhny Erzinsky granite massif, see Fig. (б). 
выделяют три фазы: 1) габброиды (габбронориты, монцогаббро), 2) монцодиориты и диориты; 3) граниты. Габброиды слагают вытянутое тело $4 \times 2$ км и находятся в юго-восточном обрамлении гранитов [Vladimirov et al., 2017]. Гранитоиды Эрзинского массива образуют протяженное в плане тело, вытянутое с юго-запада на северо-восток (рис. 1, б). По составу это порфировидные граносиениты (кварц - 15-20 об. \%, К-Nа полевой шпат - 30-45 об. \%, плагиоклаз - 10-15 об. \%, биотит - 3-5 об. \%, амфибол - 5-10 \%) и лейкограниты (кварц - 40-45 $\%$, калиевый полевой шпат - 30-35 \%, плагиоклаз 10-20 \%, биотит - 1-3\%, + роговая обманка). Для пород кислого состава характерна порфировидная структура, где вкрапленники представлены крупными (до 2 см) агрегатами калиевого полевого шпата. Следует отметить, что большинство гранитоидов имеют признаки течения и директивных структур, что косвенно указывает на их синкинематический генезис. В краевой части массива директивность исчезает либо проявлена слабо.

Возраст граносиенитов и лейкогранитов Эрзинского массива U-Pb методом по цирконам опреде-

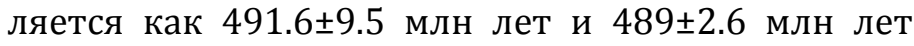
[Kozakov et al., 1999] соответственно (рис. 1).

Проведенные ранее исследования показали, что повсеместно на площади выходов кристаллического фундамента Западного Сангилена наблюдаются признаки нескольких метаморфических событий: метаморфизм М1 типа Барроу с возрастом 570525 млн лет и высокоградиентный метаморфизм низких давлений М2, связанный с внедрениями габбро-монцодиоритовых интрузивов $(525,490$, 465 млн лет), дифференциация которых проходила в промежуточных камерах [Izokh et al., 2001; Egorova et al., 2006; Shelepaev et al., 2018]. Характер метаморфической зональности в форме термального «купола» или «антиклинали» позволяет в пределах кристаллического фундамента Западного Сангилена оконтурить палеотермальный ареал регионального этапа метаморфизма М2 (рис. 1, a). В пределах концентрического ареала с поперечным размером около 75 км выделены андалузит-, силлиманити гиперстен-калишпатовые зоны метаморфизма [Kargopolov, 1991]. Кианитовая, ставролитовая и мусковитовая зоны отвечают периферийным частям ареала и содержат реликты парагенезисов M1. Петротип метаморфической зональности на участке мугурского комплекса характеризуется T-Р-параметрами в приконтактовой зоне 850$900{ }^{\circ} \mathrm{C} / 2-3$ кбар со средним температурным градиентом 60-70 ${ }^{\circ} \mathrm{C} /$ км [Kargopolov, 1991]. Здесь выделены изограды исчезновения $\mathrm{Ky}$, St, $\mathrm{Mu}$, And (+Kfs), появления Kfs, Sill, Нy. Выше изограды силлиманита наблюдается повсеместная мигматизация и присутствуют многочисленные мелкие те- ла гранитов. Р-Т-параметры метаморфизма М2: 2-4 кбар, с ростом Т в ореоле от 500 до $850{ }^{\circ} \mathrm{C}$, при $\mathrm{T}=720-750{ }^{\circ} \mathrm{C}$ на изограде гиперстена [Kargopolov, 1991]. Время формирования региональной термической аномалии соответствует времени внедрения габброидов и монцонитов Баянкольского и Эрзинского массивов и отвечает границе кембрия и ордовика (500-490 млн лет) [Izokh et al., 2001].

\section{2. МЕТОД МОДЕЛИРОВАНИЯ}

Для поиска подходящих источников тепла, объясняющих локальные термические аномалии на фоне регионального термического ареала, оказывается перспективным применение численных термомеханических моделей, описывающих эволюцию температуры вокруг движущейся магмы [Polyansky et al., 2010, 2014; Semenov, Polyansky, 2017].

Постановка задачи. Для решения задачи фракционного плавления и миграции гранитоидного расплава рассматривается область размером $80 \times 45$ км с условиями симметрии на боковых границах (означают, что область по горизонтали во много раз больше, чем по вертикали), верхняя грань соответствует поверхности земли с постоянной температурой $0{ }^{\circ} \mathrm{C}$. На нижней грани в средней части задан тепловой источник шириной 20 км с постоянной температурой $1300{ }^{\circ} \mathrm{C}$, на остальных участках принимаются условия теплоизоляции. Температура в магматическом очаге принята в соответствии с данными Р.А. Шелепаева [Shelepaev, 2006] о составе родоначальной магмы габброидов Эрзинского массива. В начальный момент времени задается линейный рост температуры в коре по глубине от 0 до $600{ }^{\circ} \mathrm{C}$. Для расчета используется структурированная расчетная сетка 8000 на 4500 ячеек с размером ячейки 10 м.

Область коры разделена на три слоя, соответствующих нижней («гранулитовой»), средней («гранитной») и верхней («осадочно-метаморфической») коре. Трехслойное строение коры Сангиленского массива принято согласно плотностной модели земной коры восточной части Алтае-Саянской области, построенной на основе сейсмологических данных и данных о гравитационных аномалиях [Vasilevsky et al., 1985]. По этой модели средняя плотность пород верхнего слоя сангиленской части

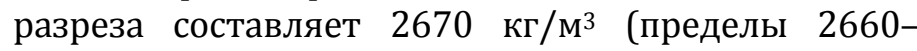
2690 кг/м33). Мощность верхнего слоя коры, состоящего из осадков и метапелитов, меняется от 12 до 15 км. Подстилающий слой представлен гранитоидными формациями с плотностью 2780 кг/м³ (возможны вариации 2770-2790 кг/м³). Нижняя кора соответствует по составу гранулитовым образова- 
ниям со средней плотностью 2900 кг/м³ (28802910 кг/м³). Глубина границы Мохоровичича модели согласована с имеющимися сейсмическими и сейсмологическими данными и составляет 50-52 км [Yegorova, Pavlenkova, 2015; Reference, 2013; Zorin, 1999]. Для сокращения параметров задачи и упрощения интерпретации результатов плотностные параметры верхней и средней коры, а также мощности всех слоев коры были приняты одинаковыми.

Петрологическая модель коры в отношении способности генерировать расплав рассматривалась в упрощенном приближении. Согласно [Bea, 2012], степень «фертильности» коры (по содержанию легкоплавких и летучих компонентов) снижается с глубиной в (мета)пелитовом, гранитном и гранулитовом слое. В соответствии с оценками объемной доли расплава в мигматитах термального ареала массива Этив (Шотландия) [Droop, Brodie, 2012] задавались температуры «влажного» плавления в интервале $50{ }^{\circ} \mathrm{C}$ для каждого слоя коры (рис. 2, a). Плотность и доля расплава в диапазоне плавления меняется линейно, вне этого диапазона задается константное значение с максимальной степенью плавления 0.75. Принималось ступенчатое увеличение плотности расплава/породы с глубиной на границах слоев коры. Вязкость для всей расчетной области устанавливалась согласно экспериментальной зависимости:

$$
\eta=\exp \left(\frac{-c \Phi}{n}\right) A^{\frac{-1}{n}}\left[\dot{\varepsilon}_{l l}\right]^{\frac{1-n}{n}} \exp \left(\frac{H}{n R T}\right)
$$

где $T$ - температура, $\dot{\varepsilon}_{l l} \equiv \frac{1}{2} d_{i j} d_{i j}$ - скорость деформации, $\Phi$ - доля расплава, $c=30-45$ - эмпирическая константа, реологические параметры $n=2.6$; $A=4 \mathrm{e}-21$ Па-" $^{-1}$ c $^{-1} H=134$ КДж/моль соответствует поведению водонасыщенного кварцита [Kronenberg, Tullis, 1984], $R$ - универсальная газовая постоянная.

Для двухфазной среды в приближении сжимаемой жидкости решается система уравнений НавьеСтокса: уравнение неразрывности, уравнение движения и уравнение сохранения энергии. Подробное описание системы уравнений, используемых в модели, приведено в статье [Semenov, Polyansky, 2017] и здесь не повторяется. Для решения задачи применяется вычислительный пакет ANSYS Fluent [ANSYS Fluent Theory Guide, 2009], в котором реализованы численные алгоритмы для решения задач течения нелинейно-вязкой, температурно-зависимой жидкости.

\section{3. РЕЗУЛЬТАТЫ МОДЕЛИРОВАНИЯ}

Процесс плавления и миграции расплава можно разбить на прогрессивный этап и регрессивный, при котором происходит остывание и кристаллизация. Остановимся более подробно на прогрессивном этапе, завершение которого характеризует пиковые условия метаморфизма.

Начальный этап состоит в нагревании нижней коры от источника, и при достижении температуры $800{ }^{\circ} \mathrm{C}$ начинается плавление. Движение расплава вверх происходит, когда его доля достигает порога $\sim 7 \%$. При меньшей доле расплав остается несвязным и для течения подъемной силы недостаточно. Процесс протекает в виде формирования множества локальных гранитоидных интрузий, которые образуются над кровлей базитовой камеры (рис. 3 и 4, 24 тыс. лет). Их вершины являются самой горячей частью, они проплавляют путь, по которому высокотемпературный расплав от источника поступает быстро вверх и образует канал. Этот этап длится, пока расплав не достигает границы между нижней и средней корой (рис. 3, 4, 30 тыс. лет). Степень плавления гранулитовой части коры снижается до 6 об. \% в ее верхнем слое. Далее начинается взаимодействие расплава с веществом средней коры. Первые порции расплава, достигшие границы между нижней и средней корой, не в состоянии проплавить среднюю кору. Начинается накопление поступающего расплава. Каналы, заполненные магмой, в нижней коре прогревают окружающие породы и сливаются в единое тело. На данный момент формируется очаг на границе нижней и средней коры в форме лополита. Это тело начинает работать как источник тепла, и по достижении $750{ }^{\circ} \mathrm{C}$ в средней коре формируются пальцеобразные интрузии (рис. 3 и 4, 100 тыс. лет). Этот этап является практически полным повторением процесса плавления в нижней коре.

Далее процесс замедляется, так как на меньших глубинах температура ниже и требуется больше энергии для прогрева и образования канала в средней части коры, несмотря на более легкоплавкий состав. Степень плавления в средней коре убывает от 15 до $6 \%$ снизу вверх (рис. 5). На последнем этапе образуется единичный канал в средней части, проникающий в верхнекоровый слой на глубину 12-13 км (3.5 кбар) (рис. 5). Дайкообразный канал имеет ширину 200-300 м и не в состоянии прогреть область вокруг себя до температуры выше солидуса, чтобы поддерживать условия существования магмопроводника. Происходит перемешивание (гибридизация) магм, а именно нижнекоровый расплав из надочаговой области массивно проникает в среднюю кору и в результате этих «импульсов» внедряется вплоть до верхней коры в объеме не более 5-6 об. \%. Максимальная высота внедрения интрузии из средней части достигает 13 км, магма содержит в себе до $6 \%$ вещества коры из нижней части в вершине интрузии. В дальнейшем процесс «инъекций» приобретает пульсационный характер. 
(a)

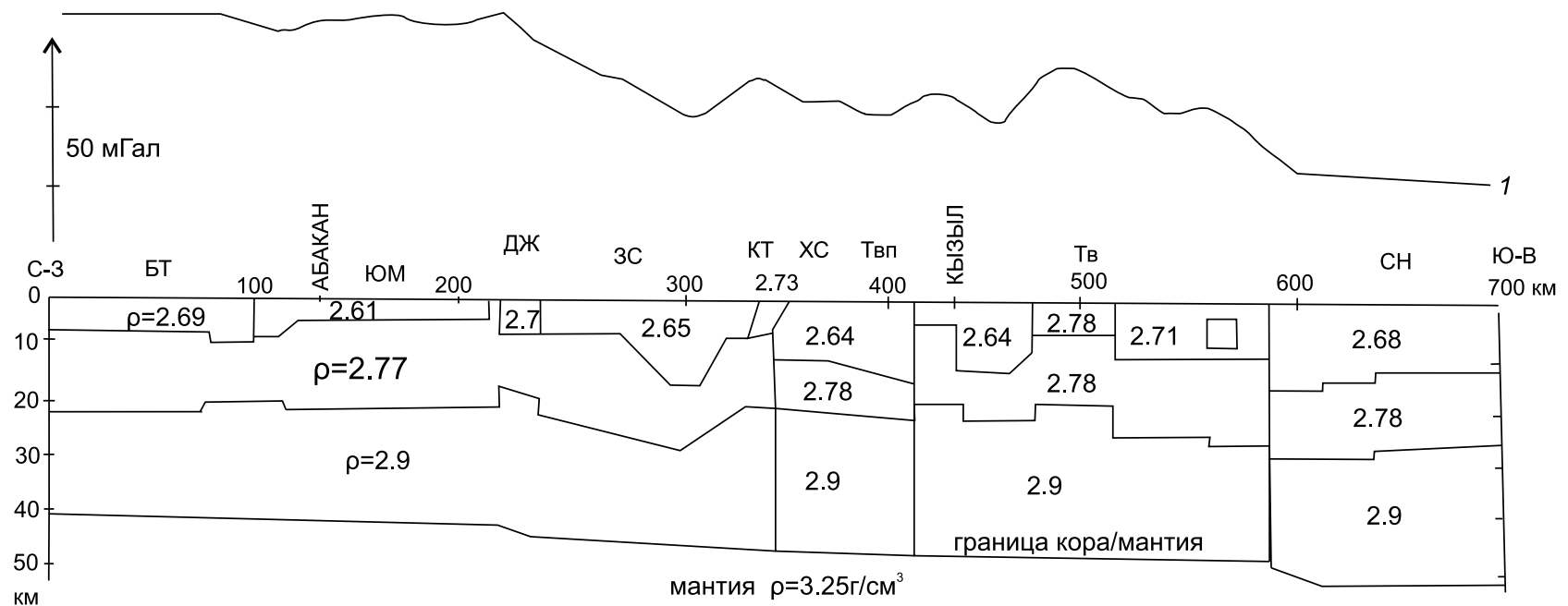

(б)

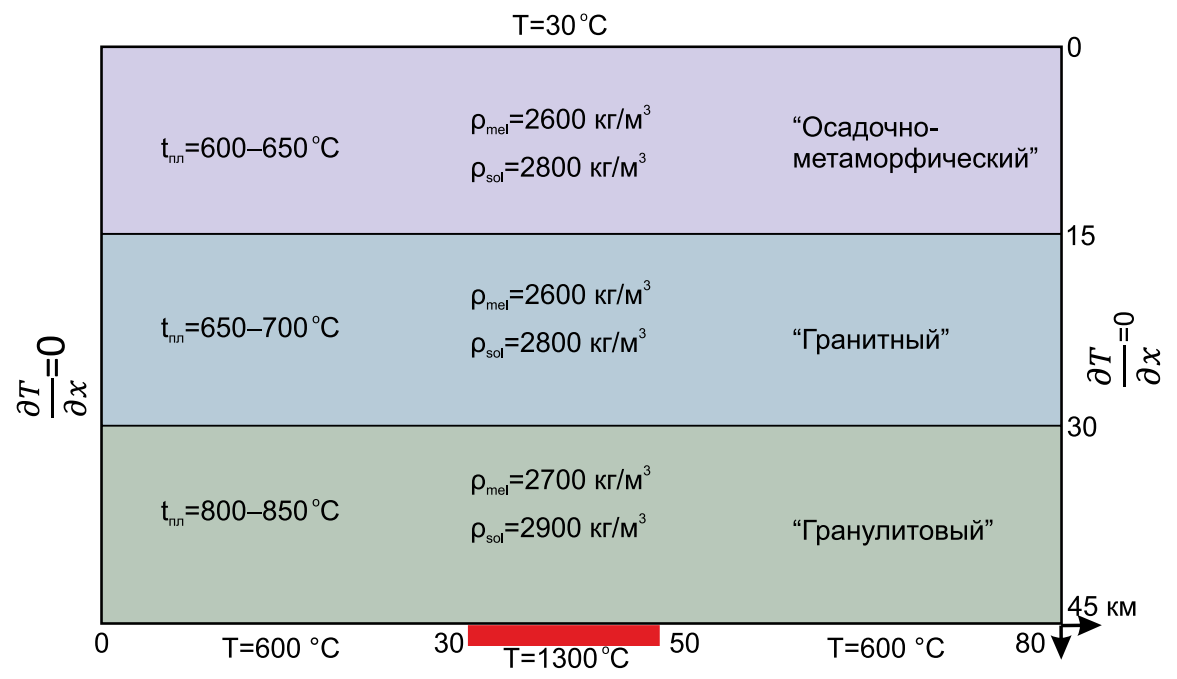

Рис. 2. (a) - плотностная модель земной коры восточной части Алтае-Саянской области [Vasilevsky et al., 1985]. Macсивы коры: Минусинско-Западно-Саянский (БТ - Батенево-Беллыкское поднятие, ЮМ - Южно-Минусинская впадина, Дж - Джебашский блок, ЗС - Центрально-Западно-Саянский блок, КТ - Куртушибинский блок); ХемчикСистигхемский блок (ХC - Хемчик-Систигхемский прогиб, Твп - Тувинский прогиб); Тувино-Монгольский массив (Тв - Тувинская зона, СН - Сангиленский блок). 1 - профиль аномалий силы тяжести в редукции Буге, масштаб аномалий приведен слева. (б) - постановка задачи фракционного плавления 3-слойной коры. Геометрия расчетной области, представляющей трехслойную кору. Указаны температура плавления и плотности расплавов и породы каждого слоя коры. В средней части основания коры (30-50 км) задан тепловой базитовый источник с постоянной температурой $1300^{\circ} \mathrm{C}$.

Fig. 2. (a) - crust density model of the Altai-Sayan region [Vasilevsky et al., 1985]. Crust massifs: Minusinsk-West Sayan massif (БT - Batenevo-Bellyk uplift, ЮM - South Minusinsk depression, Дж - Dzhebash block, 3C - Central-West Sayan block, KT - Kurtushiba block); Khemchik-Sistigkhem block (XС - Khemchik-Sistigkhem trough, Твп - Tyva trough); Tyva-Mongolian massif (Тв - Tyva zone, $\mathrm{CH}$ - Sangilen block). 1 - gravity anomalies in Bouguer reduction (the scale is shown on the left). (б) - problem of fractional melting of the three-layer crust. The geometry of the computational domain representing the three-layer crust. Melting temperature and density values are given for each layer of the crust. A thermal source (constant temperature of $\left.1300^{\circ} \mathrm{C}\right)$ is specified for the middle part of the crustal basement $(30-50 \mathrm{~km})$.

\section{4. ОБСУжДЕНИЕ}

В выполненном моделировании важным является вопрос о реальном механизме плавления. Плавление в природе всегда остается неполным, поэтому мы имеем дело с частичным плавлением. Рассмат- риваются две крайние модели, описывающие плавление: фракционное (неравновесное) (fractional melting) и порционное (равновесное) (batch melting). При фракционном плавлении: а) расплав извлекается сразу, как только он создается, б) бесконечная малая часть только что появившегося расплава 

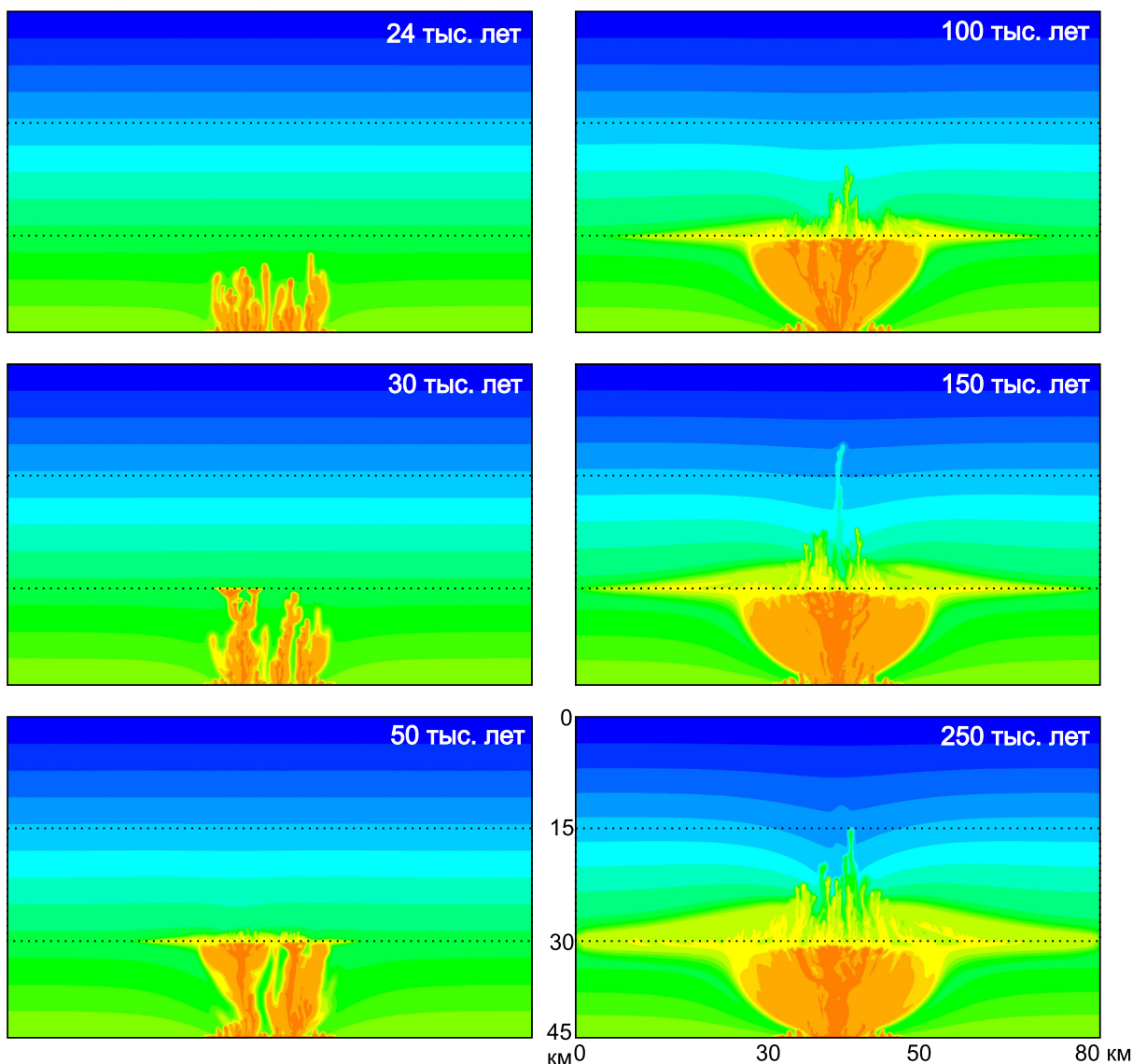

Рис. 3. Результаты расчетов эволюции температурного поля с единой шкалой для всех моментов времени с начала действия теплового источника. За 30 тыс. лет интрузия достигает границы нижней и средней коры, на момент 150 тыс. лет проникает на уровень верхней коры. Максимальный подъем магмы до глубины 12-13 км фиксируется на момент 128 тыс. лет (в деталях см. рис. 5). Пунктирными линиями показаны границы слоев коры.

Fig. 3. Estimations characterizing the evolution of the temperature field with a single scale for all time points since the beginning of the activity of the heat source. It takes $30 \mathrm{Ka}$ for the intrusion to reach the boundary of the lower and middle crust. At $150 \mathrm{Ka}$, it reaches the level of the upper crust. The maximum rise of magma to a depth of 12-13 km is recorded at $128 \mathrm{Ka}$ (see Fig. 5 for details). Dashed lines show the boundaries of the crustal layers.

находится в равновесии с твердым остатком, в) происходит изменение валового состава, г) расплав экстрагируется при низких процентах плавления (обычно принимаются первые \%). При порционном плавлении: а) доля водосодержащего расплава достигает 20-70 \%, из которых 80-95 об. \% экстрагируется и $5 \%$ остается на месте в рестите [Clemens, 2006; Sawyer, 2001], б) расплав полностью уравновешивается с твердым остатком, в) сохраняется постоянный валовый состав, г) расплав становится мобильным при достижении определенного порога проницаемости, до этого момента происходит его сегрегация.

Классические петрологические схемы плавления, а именно фракционного и порционного, являются идеализированными и физически некорректными [Tirone, 2018]. Порционное плавление подразумевает, что продукты плавления всегда находят- ся в контакте с источником, что часто противоречит геохимическим данным. Фракционное плавление означало бы, что расплав не может существовать в магматическом очаге, так как вся жидкая фаза мгновенно извлекается. Обе схемы представляют статические, вневременные модели: область плавления неподвижна, расплав либо не перемещается, либо экстрагирует мгновенно. Чтобы избежать этих нереальных физических ограничений оказывается перспективным использование петролого-термомеханических, динамических моделей плавления с учетом взаимодействия как минимум двух фаз: твердого остатка и мобильного расплава. Такой подход основан на выполнении законов сохранения движения, массы и энергии и реализуется с использованием численных методов для описания плавления в океанической коре [Elliot, Spiegelman, 2003] и мантии [Hewitt, 2010]. 

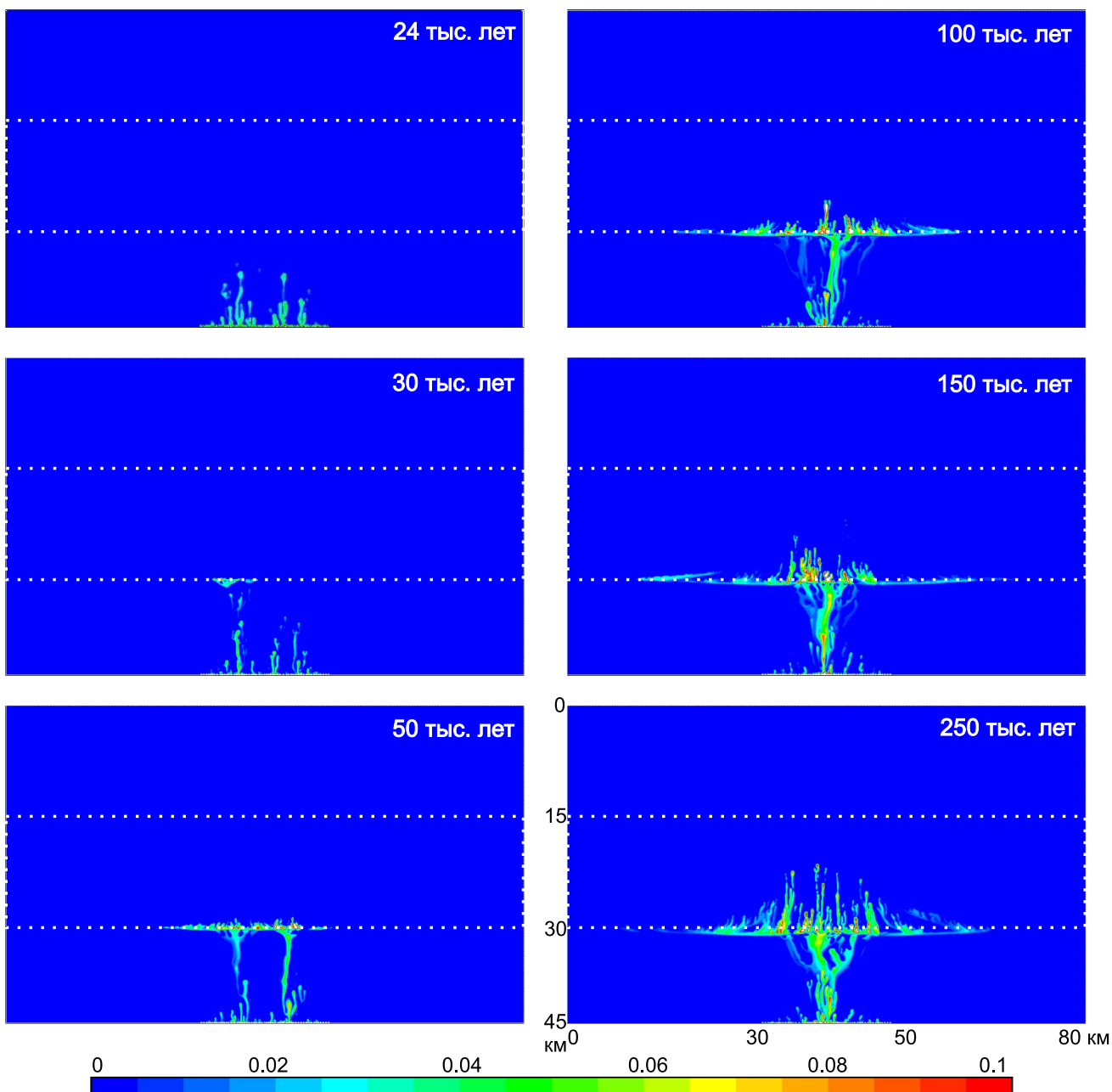

Рис. 4. Эволюция степени плавления нижней и средней коры (в долях расплава с ограниченной шкалой 0-10 \% для всех моментов времени) вне зависимости от состава расплава. Максимальная степень плавления в средней коре достигает $15 \%$, в нижней коре $-6 \%$.

Fig. 4. Evolution of the degree of melting of the lower and middle crust (in melt proportions with a limited scale of 0-10 \% for all time points) regardless of the melt composition. Maximum melting amounts to $15 \%$ in the middle crust and $6 \%$ in the lower crust.

Ранее в ряде работ [Polyansky et al., 2009, 2010, $2016,2017]$ использовалась модель порционного (batch) плавления вещества гранитной коры, в которой доля расплава (степень плавления) остается постоянной. Характерной формой при этом механизме плавления являются магматические диапиры [Schmeling et al., 2019]. В качестве примера приведен результат моделирования процесса формирования термального ареала вокруг гранитоидного диапира, возникшего над базитовым магматическим источником тепла в основании коры (рис. 6). Скорости подъема диапиров в земной коре (0.8 см/год) более чем на порядок ниже скорости миграции расплава при фракционном плавлении, которая согласно вышеприведенных моделей составляет 25 см/год.

Зональность представляет собой термальный «купол», формирующийся над базитовой интрузией с температурой $1200{ }^{\circ} \mathrm{C}$, возникший в процессе диа- пирового подъема частично расплавленного, менее плотного материала коры. На рис. 6 модельное поле температуры и давления вокруг диапира совмещено с наложенными полями устойчивости наблюдаемых минеральных ассоциаций (границы полей устойчивости по [Pattison et al., 2003]. Размер температурной аномалии в поперечнике (30 км) сравним по масштабу с наблюдаемой региональной зональностью Западного Сангилена. Таким образом можно смоделировать природу концентрического распределения изоград региональной метаморфической зональности. В сечении предполагаемого эрозионного уровня (4 кбар) показано положение изоград. Поле устойчивости андалузита (+Kfs) занимает прикровельную область термального купола и ограничено по давлению в узком интервале глубин. Нельзя подобрать горизонтальный срез на уровне 3-4 кбар, который бы соответствовал появ- 


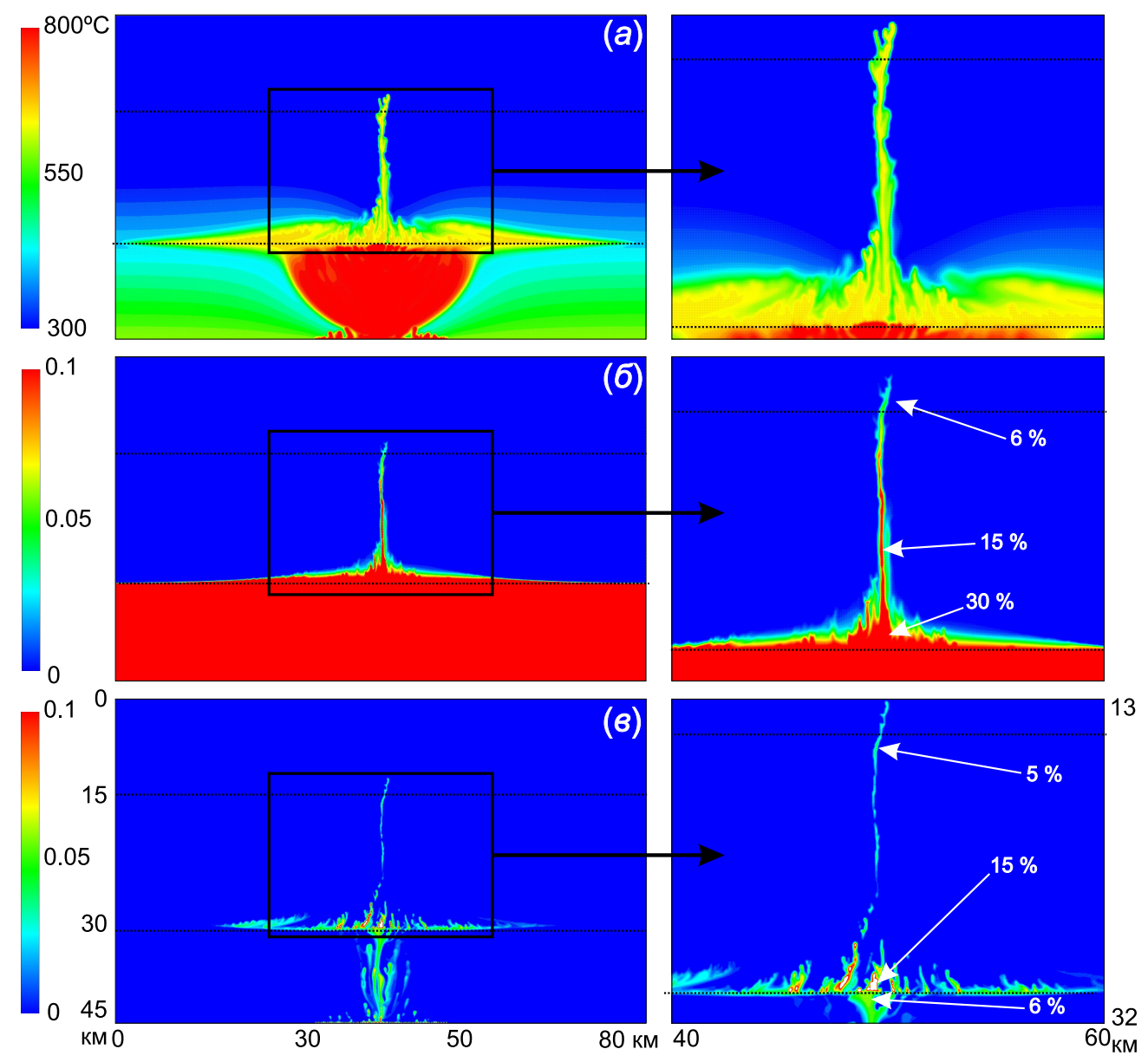

Рис. 5. Распределения температуры (a), доли частично расплавленного гранулита (б), степени плавления (в) на момент максимального подъема магмы (128 тыс. лет с начала действия теплового источника). (a) - контуры распределения температуры в интервале $300-800{ }^{\circ} \mathrm{C}$. Температурные поля ниже 300 и выше $800{ }^{\circ} \mathrm{C}$ показаны синим и красным, соответственно. В нижнекоровом слое достигается температура $950{ }^{\circ} \mathrm{C}$. (б) - содержание компонента нижней коры (ограниченная шкала от 0 до 10 \%). В канале наблюдается смешение магм нижнекорового (до 15 \%) и среднекорового состава. (в) - доля расплава (независимо от состава) в диапазоне 0-10 \% при максимальной степени плавления до 15 \% над границей нижней и средней коры. Максимальный уровень подъема магмы - 13 км, магма содержит в себе до 6 \% нижнекорового компонента в вершине интрузии.

Fig. 5. Distribution of temperature (a), partially molten granulite (б), melting degree $(8)$ at the time of maximum magma ascent (128 Ka from the heat source start). (a) - temperature contours in the $300-800{ }^{\circ} \mathrm{C}$ range. Temperature fields: blue - below $300{ }^{\circ} \mathrm{C}$, red - above $800{ }^{\circ} \mathrm{C}$. In the lower-crust layer, the temperature amounts to $950{ }^{\circ} \mathrm{C}$. (б) - the content of the lower crust component (limited scale of 0-10\%). Mixing of the lower-crust (up to $15 \%$ ) and middle-crust magmas takes place in the channel. (8) - proportion of the melt (regardless of the composition) in the $0-10 \%$ range in case of the maximum degree of melting up to $15 \%$ above the boundary of the lower- and middle-crust layers. The maximum magma ascent is $13 \mathrm{~km}$; the lower-crust component in this magma amounts to almost $6 \%$ at the intrusion top.

лению и гиперстеновой, и андалузит-Кfs зоны. Это говорит о том, что причиной появления гиперстеновой зоны является независимый процесс, наложенный на раннюю стадию метаморфизма.

Принципиально иной является динамика подъема магм и формы всплывающего вещества при фракционном плавлении: над очагом образуются многочисленные пути миграции расплава сквозь твердую матрицу, которые в процессе подъема концентрируются в единый канал (рис. 7, a). В результате моделирования можно сделать вывод, что движение и подъем начинаются при содержании примерно 5-7 об. \% расплава в среде. Это можно интерпретировать так, что расплав уже не удерживается в матриксе, а связан межзерновыми каналами, что позволяет ему мигрировать вверх как более легкому компоненту. Согласно данным [Rosenberg, Handy, 2005], для гранитных магм существует два реологических порога, при превышении которых поведение расплава резко меняется. Первый из них - порог, при котором расплав становится мобильным в межзерновом пространстве, второе пороговое значение доли расплава (в диапазоне 20-40 \%) определяет деструкцию твердого скелета и пере- 


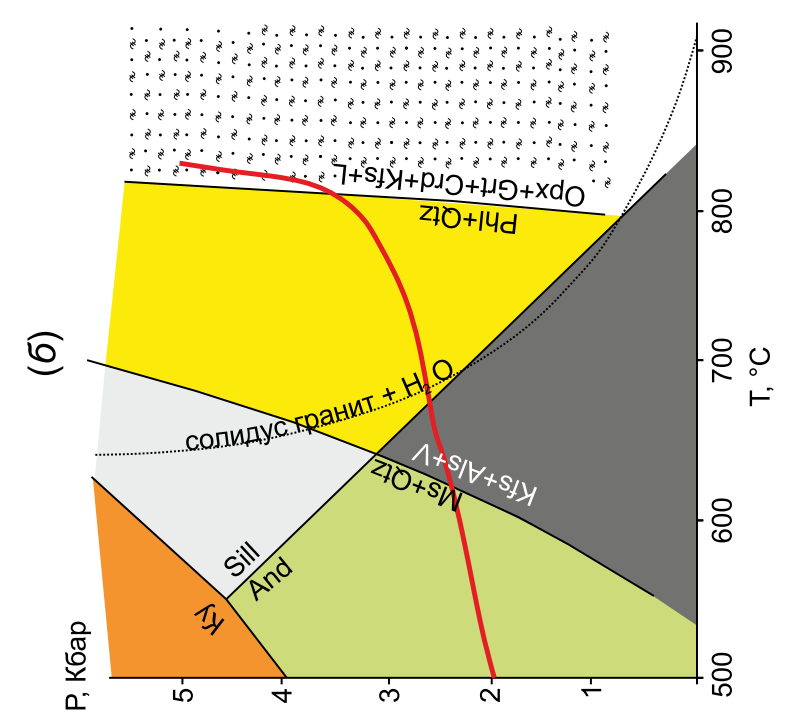

mபy+1I!S+
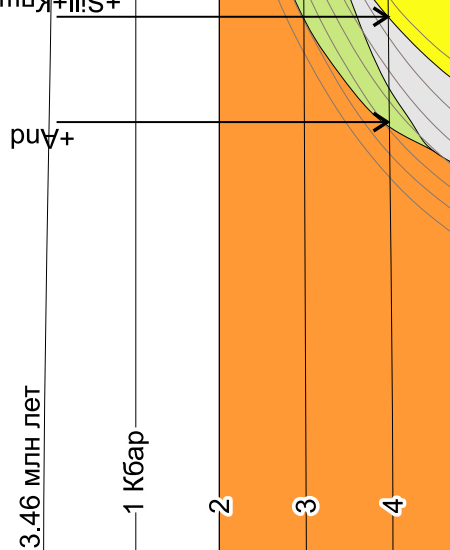

옹

\section{ดे}
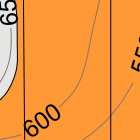

$60^{\circ}$

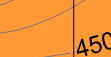

$\nabla^{0}$

450

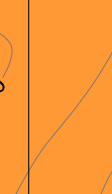

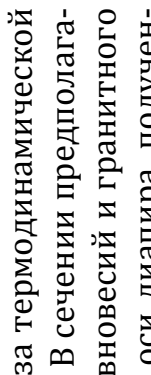

ก็

ปั่

萦瓷希

×

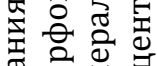

兽焉志

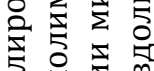

导完

窎壳

용

蛋壳

T्ञ

可尔

$\sum_{i} \sum^{5}$

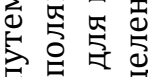

ป

重寻完

స్.

蛋起

$\sum_{m}^{\pi} \begin{aligned} & \pi \\ & 0\end{aligned}$

$\stackrel{2}{\stackrel{2}{0}}$

응

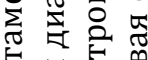

荥点

ใิ

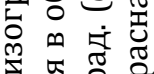

四 苋

造

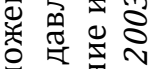

要

-

코ำ

ญ 율

웜

ฮี

छृ

ฮ류.

हี ญ

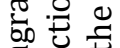

肎 is n

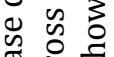

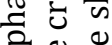

을

్․

궝

है

बे

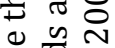

全

is o to

范

次

을 은

สิ ปั

D م

흠워

ฮิ ம்

ส

它

ब्य

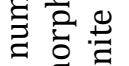

츠 주

궁

总䒕.

퓽료

记

के

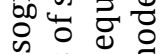

ह 들

量实

of की

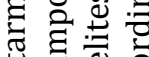

记

顿苛

ป ᄃ

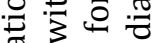

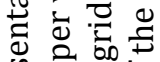

\& .

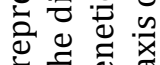

ए

:

है

$0 \stackrel{0}{0}$

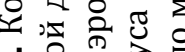

๑ 管 岂

范芯 
(a)

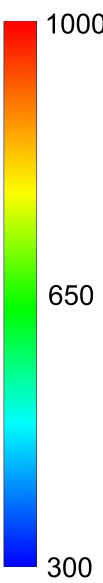

300

\section{(б)}

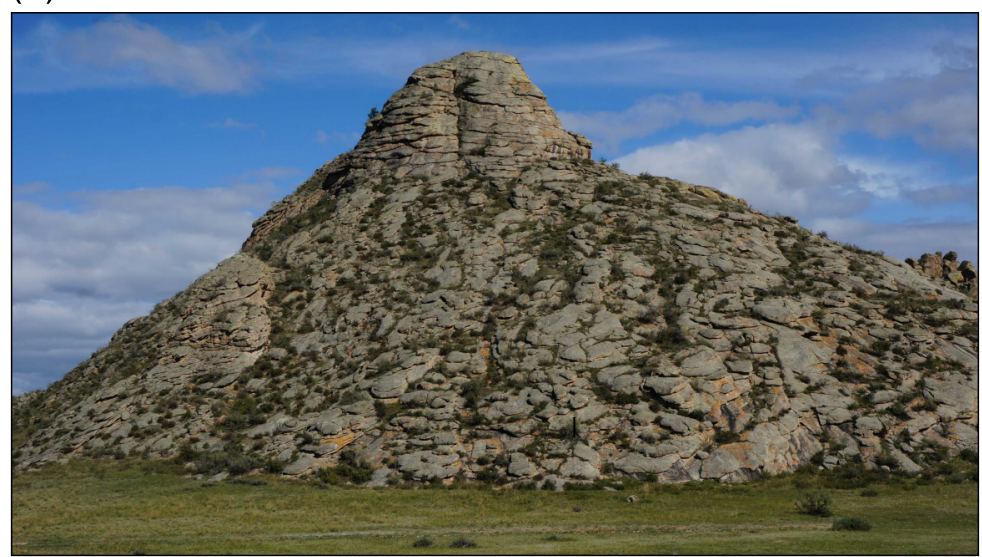

(в)

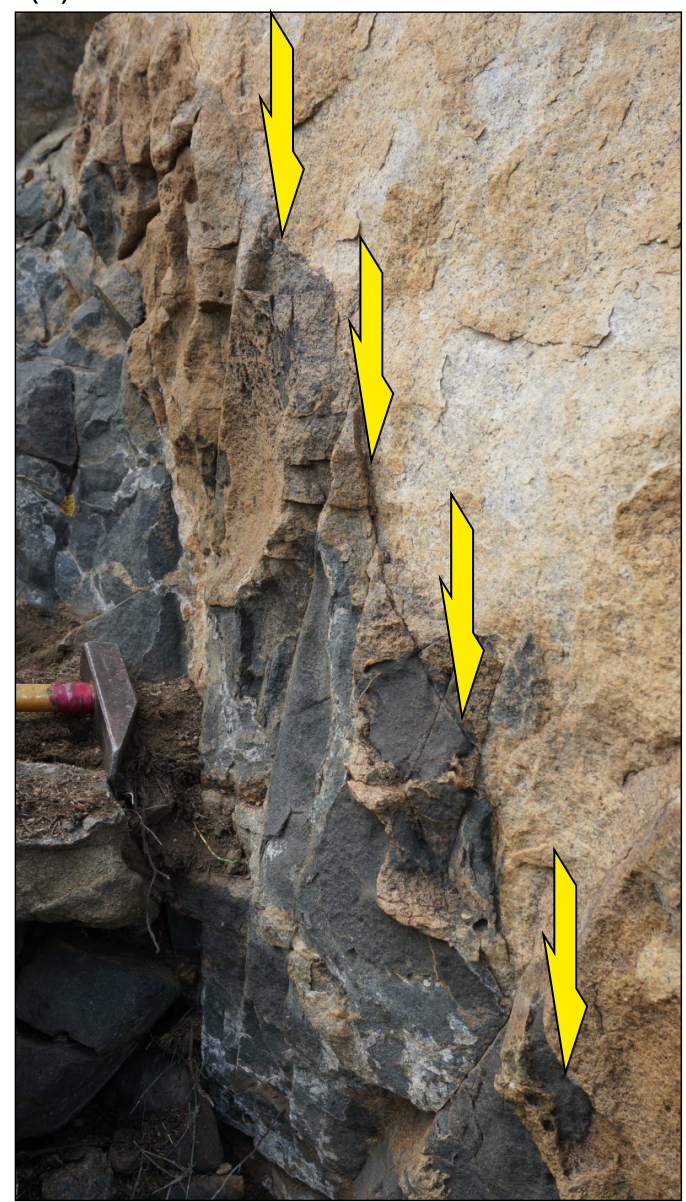

Рис. 7. (a) - распределение температуры в момент максимального подъема магмы в верхней коре (128 тыс. л.); (б) типичная структура выветривания гранитного штока Матутского гранитогнейсового массива (г. Бумбату, ЭрзинНарынский тектонический блок), размер гранитного «конуса» 160 м по горизонтали, 30 м по вертикали; (в) - контакт между салической и мафитовой зонами минглинг-даек Нижнеэрзинского гранитоидного массива. Стрелками показан вертикальный контакт без признаков контактово-метаморфических преобразований.

Fig. 7. (a) - temperature distribution pattern at the maximum magma ascent in the upper crust (128 Ka). (б) - typical weathering structure of a granitic stock at the Matut granite-gneiss massif (Bumbatu mountain, Erzin-Naryn tectonic block); the size of the granitic 'cone' is $160 \mathrm{~m}$ (horizontal) $\times 30 \mathrm{~m}$ (vertical). $(\theta)-$ contact between the salic and mafic zones of mingling dikes at the Nizhny Erzin granitoid massif. Arrows mark a vertical contact without any signs of contact-metamorphic transformations.

ход среды к «кашеобразному», квазижидкому состоянию. Таким образом, наши оценки минимальной доли расплава 5-6\% близки к оценке величины «перколяционного порога» $7 \%$ [Rosenberg, Handy, 2005], в отличие от ранее принятой доли 2025 об. \% по данным [Vigneresse et al., 1996].

Так как в данном расчете мы использовали единый закон вязкости для всей коры, а различия между слоями заданы только по плотности и температуре плавления, можно сделать вывод, что плотностные границы в коре в первую очередь являются барьерами для подъема расплава. Расплав накапливается на границе раздела, и формируется нижнекоровый промежуточный магматический очаг, степень плавления в котором составляет около 6 об. \%, что согласуется с данными о степени плавления кислых гранулитов комплекса Кутна Гора (Богемский массив) [Nahodilová et al., 2011]. Установлена возможность подъема в верхнюю часть коры вещества из нижней части в объемной доле не более 5-6 \%. При этом гибридная магма может содержать в канале до 25 \% вещества нижней коры. Эти результаты говорят о значительной гибридизации исходной магмы компонентами средней и верхней коры и о возможности формирования минглинг-структур [Vladimirov et al., 2017; Semenov, Polyansky, 2017].

Моделирование режима фракционного плавления показало образование локальных гранитоидных интрузий шириной примерно 200-300 м (рис. 7, б), которые проникают на глубины до 13 км (3.5 кбар) с пиковой температурой в апикальной ча- 
сти до $650{ }^{\circ} \mathrm{C}$. Они кратковременны (до 250 тыс. лет) и имеют пульсационный характер. Ни в одной из моделей гранитоидные интрузивы не прогревали окружающую область и не формировали контактово-метаморфические ареалы с размером от 0.5 до 5.0 км, подобные зональностям баянкольского и мугурского массивов [Kargopolov, 1991]. Повсеместно в пределах Эрзинского комплекса наблюдаются секущие «холодные» контакты гранитоидов минглинг-даек с вмещающими гранат-биотиткордиеритовыми сланцами (рис. 7, в) [Karmysheva et al., 2015], поэтому в качестве теплового источника метаморфических ареалов требуется допустить присутствие более высокотемпературной магмы на уровне границ между верхней и средней, средней и нижней корой. Ранее было показано, что для Западного Сангилена устанавливается связь метаморфизма HT/LP-типа с базитовыми интрузиями [Egorova et al., 2006].

\section{5. ЗАКЛЮЧЕНИЕ}

Таким образом, этапы развития метаморфической термальной «антиклинали» могли быть обусловлены разным режимом плавления материала коры: на начальном этапе - порционного типа, на завершающем - фракционного. Смена режимов плавления от условий в «закрытой» системе к условиям фракционного плавления в «открытой» системе, вероятно, определялась тектоническими факторами. Процесс внедрения базитовых магм с формированием промежуточных камер в верхней коре - предмет дальнейших исследований.

\section{6. БЛАГОДАРНОСТИ}

Работа выполнена при поддержке Президиума СО РАН (проекты № 53, 44) и РФФИ (проект № 17-05-00848).

\section{7. ЛИТЕРАTУРА / REFERENCES}

\section{ANSYS Fluent Theory Guide, 2009. Release 12.1.}

Bea F., 2012. The sources of energy for crustal melting and the geochemistry of heat-producing elements. Lithos 153, 278-291. https://doi.org/10.1016/j.lithos.2012.01.017.

Brown M., 2006. Duality of thermal regimes is the distinctive characteristic of plate tectonics since the Neoarchean. Geology 34 (11), 961-964. https://doi.org/10.1130/G22853A.1.

Brown M., 2007. Metamorphic conditions in orogenic belts: a record of secular change. International Geology Review 49 (3), 193-234. https://doi.org/10.2747/0020-6814.49.3.193.

Clemens J.D., 2006. Melting of the continental crust: Fluid regimes, melting reactions, and source-rock fertility. In: M. Brown, T. Rushmer (Eds.), Evolution and differentiation of the continental crust. Cambridge University Press, Cambridge, p. 297-331.

Droop G.T.R., Brodie K.H., 2012. Anatectic melt volumes in the thermal aureole of the Etive Complex, Scotland: the roles of fluid-present and fluid-absent melting. Journal of Metamorphic Geology 30 (8), 843-864. https://doi.org/ 10.1111/j.1525-1314.2012.01001.x.

Egorova V.V., Volkova N.I., Shelepaev R.A., Izokh A.E., 2006. The lithosphere beneath the Sangilen Plateau, Siberia: Evidence from peridotite, pyroxenite and gabbro xenoliths from alkaline basalts. Mineralogy and Petrology 88 (3-4), 419-441. https://doi.org/10.1007/s00710-006-0121-0.

Elliot T., Spiegelman M., 2003. Melt migration in oceanic crustal production: a U-series perspective. In: R.L. Rudnick (Ed.), Treatise in geochemistry. Vol. 3. The crust. Elsevier-Pergamon, Oxford, p. 465-510.

Hewitt I.J., 2010. Modelling melting rates in upwelling mantle. Earth and Planetary Science Letters 300 (3-4), $264-274$. https://doi.org/10.1016/j.epsl.2010.10.010.

Izokh A.E., Kargopolov S.A., Shelepaev R.A., Travin A.V., Egorova V.V., 2001. The basic magmatism of the CambrianOrdovician stage of the Altai-Sayan folded region and the connection with it of the metamorphism of high temperatures and low pressures. In: Actual problems of geology and minerageny of Southern Siberia. Conference materials. Publishing House of Lavrentiev Institute of Hydrodynamics SB RAS, Novosibirsk, p. 68-72 (in Russian) [Изох А.Э., Каргополов С.А., Шелепаев Р.А., Травин А.В., Егорова В.В. Базитовый магматизм кемброордовикского этапа Алтае-Саянской складчатой области и связь с ним метаморфизма высоких температур и низких давлений // Актуальные вопросы геологии и минерагении юга Сибири: Материалы конференции. Новосибирск: Изд-во Института гидродинамики им. М.А. Лаврентьева СО РАН, 2001. С. 68-72].

Kargopolov S.A., 1991. Metamorphism of the Mugur zonal complex. Geologiya i Geofizika (Russian Geology and Geophysics) 32 (3), 109-119 (in Russian) [Каргополов C.A. Метаморфизм мугурского зонального комплекса // Геология и геофизика. 1991. Т. 32. № 3. С. 109-119].

Karmysheva I.V., Vladimirov V.G., Vladimirov A.G., Shelepaev R.A., Yakovlev V.A., Vasyukova E.A., 2015. Tectonic position of mingling dykes in accretion-collision system of Early Caledonides of West Sangilen (South-East Tuva, Russia). Geodynamics \& Tectonophysics 6 (3), 289-310. https://doi.org/10.5800/GT-2015-6-3-0183. 
Kelsey D.E., Hand M., 2015. On ultrahigh temperature crustal metamorphism: phase equilibria, trace element thermometry, bulk composition, heat sources, timescales and tectonic settings. Geoscience Frontiers 6 (3), 311-356. https://doi.org/10.1016/j.gsf.2014.09.006.

Kozakov I.K., Sal'nikova E.B., Bibikova E.V., Kirnozova T.I., Kotov A.B., Kovach V.P., 1999. Polychronous evolution of the paleozoic granitoid magmatism in the Tuva-Mongolia massif: U-Pb geochronological data. Petrology 7 (6), 592-601.

Kronenberg A.K., Tullis J., 1984. Flow strengths of quartz aggregates: grain size and pressure effects due to hydrolytic weakening. Journal of Geophysical Research: Solid Earth 89 (B6), 4281-4297. https://doi.org/10.1029/ JB089iB06p04281.

Nahodilová R., Faryad Sh. W., Dolejšac D., Tropper P., Konzett J., 2011. High-pressure partial melting and melt loss in felsic granulites in the Kutná Hora complex, Bohemian Massif (Czech Republic). Lithos 125 (1-2), 641-658. https://doi.org/10.1016/j.lithos.2011.03.017.

Pattison D.R.M., Chako T., Farquhar J., McFarlane C.R.M., 2003. Temperatures of granulite-facies metamorphism: constraints from experimental phase equilibria and thermobarometry corrected from retrograde exchange. Journal of Petrology 44 (5), 867-900. https://doi.org/10.1093/petrology/44.5.867.

Polyansky O.P., Babichev A.V., Korobeynikov S.N., Reverdatto V.V., 2010. Computer modeling of granite gneiss diapirism in the Earth's crust: Controlling factors, duration, and temperature regime. Petrology 18 (4), 432-446. https:// doi.org/10.1134/S0869591110040077.

Polyansky O.P., Korobeynikov S.N., Babichev A.V., Reverdatto V.V., Sverdlova V.G., 2009. Computer modeling of granite magma diapirism in the Earth's crust. Doklady Earth Sciences 429 (8), 1380-1384. https://doi.org/10.1134/ S1028334X09080315.

Polyansky O.P., Korobeynikov S.N., Babichev A.V., Reverdatto V.V., Sverdlova V.G., 2014. Numerical modeling of mantle diapirism as a cause of intracontinental rifting. Izvestiya, Physics of the Solid Earth 50 (6), 839-852. https:// doi.org/10.1134/S1069351314060056.

Polyansky O.P., Reverdatto V.V., Babichev A.V., Sverdlova V.G., 2016. The mechanism of magma ascent through the solid lithosphere and relation between mantle and crustal diapirism: numerical modeling and natural examples. Russian Geology and Geophysics 57 (6), 843-857. https://doi.org/10.1016/j.rgg.2016.05.002.

Polyansky O.P., Semenov A.N., Vladimirov V.G., Karmysheva I.V., Vladimirov A.G., Yakovlev V.A., 2017. Numerical simulation of magma mingling (case of Bayankol gabbro-granite series, Sangilen, Tuva). Geodynamics \& Tectonophysics 8 (2), 385-403 (in Russian) [Полянский О.П., Семенов А.Н., Владимиров В.Г., Кармышева И.В., Владимиров А.Г., Яковлев В.А. Численная модель магматического минглинга (на примере Баянкольской габбро-гранитной серии, Сангилен, Тува) // Геодинамика и тектонофизика. 2017. Т. 8. № 2. C. 385-403]. https://doi.org/ 10.5800/GT-2017-8-2-0247.

Reference Geological and Geophysical Profiles of Russia (Atlas), 2013. Deep seismic sections of GSS profiles constructed in the period from 1972 to 1995. Electronic edition. Rosnedra, VSEGEI, St. Petersburg (in Russian) [Атлас «Опорные геолого-геофизические профили России». Глубинные сейсмические разрезы по профилям ГСЗ, отработанным в период с 1972 по 1995 год. Электронное издание. СПб.: Роснедра, ВСЕГЕИ, 2013]. Available from: https://vsegei.ru/ru/info/seismic/ (last accessed March 25, 2019).

Rosenberg C.L., Handy M.R., 2005. Experimental deformation of partially melted granite revisited: implications for the continental crust. Journal of Metamorphic Geology 23 (1), 19-28. https://doi.org/10.1111/j.1525-1314.2005. 00555.x.

Sawyer E.W., 2001. Melt segregation in the continental crust: Distribution and movement of melt in anatectic rocks. Journal of Metamorphic Geology 19 (3), 291-309. https://doi.org/10.1046/j.0263-4929.2000.00312.x.

Semenov A.N., Polyansky O.P., 2017. Numerical modeling of the mechanisms of magma mingling and mixing: A case study of the formation of complex intrusions. Russian Geology and Geophysics 58 (11), 1317-1332. https:// doi.org/10.1016/j.rgg.2017.11.001.

Schmeling H., Marquart G., Weinberg R., Wallner H., 2019. Modelling melting and melt segregation by two-phase flow: new insights into the dynamics of magmatic systems in the continental crust. Geophysical Journal International, 217 (1), 422-450. https://doi.org/10.1093/gji/ggz029.

Shelepaev R.A., 2006. Evolution of Basic Magmatism, Western Sangilen (South-Eastern Tuva). Author's brief thesis (Candidate of Geology and Mineralogy). Novosibirsk, 16 p. (in Russian) [Шелепаев Р.А. Эволюция базитового магматизма Западного Сангилена (Юго-Восточная Тува): Автореф. дис. ... канд. геол.-мин. наук. Новосибирск, 2006. 16 с.].

Shelepaev R.A., Egorova V.V., Izokh A.E., Seltmann R., 2018. Collisional mafic magmatism of the fold-thrust belts framing southern Siberia (Western Sangilen, southeastern Tuva). Russian Geology and Geophysics 59 (5), 525-540. https:// doi.org/10.1016/j.rgg.2018.04.006.

Sokol E.V., Polyansky O.P., Semenov A.N., Reverdatto V.V., Kokh S.N., Devyatiyarova A.S., Kolobov V.Yu., Khvorov P.V., Babichev A.V., 2019. High-grade contact metamorphism in the Kochumdek River valley (Podkamennaya Tunguska basin, East Siberia): Evidence for Magma Flow. Russian Geology and Geophysics 60 (4), 386-399. https://doi.org/ 10.15372/RGG2019088.

Tirone M., 2018. Petrological geodynamics of mantle melting II. AlphaMELTS+ multiphase flow: dynamic fractional melting. Frontiers in Earth Science 6, Article 18. https://doi.org/10.3389/feart.2018.00018. 
Vasilevsky A.N., Boldyrev M.A., Mikheev V.V., Dergachev A.A., Krasavin V.V., Kirin Yu.M., Fomin Yu.N., Filina A.G., Blagovidova T.Ya., Kuchai O.A., 1985. Scientific and Technical Report of the Altai-Sayan Experimental-Methodical Seismological Expedition. Publishing House of the Institute of Geology and Geophysics, Siberian Branch of the USSR Acad. Sci., Novosibirsk, 243 p. (in Russian] [Василевский А.Н., Болдырев М.А., Михеев В.В., Дергачев А.А., Красавин В.В., Кирин Ю.М., Фомин Ю.Н., Филина А.Г., Благовидова Т.Я., Кучай О.А. Научно-технический отчет Алтае-Саянской опытно-методической сейсмологической экспедиции. Новосибирск: Изд-во ИГиГ СО АН СССР, 1985. 243 c.].

Vigneresse J.L., Barbey P., Cuney M., 1996. Rheological transitions during partial melting and crystallization with application to felsic magma segregation and transfer. Journal of Petrology 37 (6), 1579-1600. https://doi.org/10.1093/ petrology/37.6.1579.

Vladimirov A.G., Karmysheva I.V., Yakovlev V.A., Travin A.V., Tsygankov A.A., Burmakina G.N., 2017. Thermochronology of mingling dykes in west Sangilen (south-east Tuva, Russia): evidence of the collapse of the collisional system in the north-western edge of the Tuva-Mongolia massif. Geodynamics \& Tectonophysics 8 (2), 283-310 (in Russian) [Владимиров В.Г., Кармышева И.В., Яковлев В.А., Травин А.В., Цыганков А.А., Бурмакина Г.Н., 2017. Термохронология минглинг-даек западного Сангилена (юго-восточная Тува): свидетельства развала коллизионной системы на северо-западной окраине Тувино-Монгольского массива // Геодинамика и тектонофизика. 2017. T. 8. № 2. C. 283-310]. https://doi.org/10.5800/GT-2017-8-2-0242.

Yegorova T.P., Pavlenkova G.A., 2015. Velocity-density models of the Earth's crust and upper mantle from the Quartz, Craton, and Kimberlite superlong seismic profiles. Izvestiya, Physics of the Solid Earth 51 (2), 250-267. https:// doi.org/10.1134/S1069351315010048.

Zorin Y.A., 1999. Geodynamics of the western part of the Mongolia-Okhotsk collisional belt, Trans-Baikal region (Russia) and Mongolia. Tectonophysics 306 (1), 33-56. https://doi.org/10.1016/S0040-1951(99)00042-6.

Олег Петрович Полянский

докт. геол.-мин. наук, зав. лабораторией

Институт геологии и минералогии им. В.С. Соболева СО РАН 630090, Новосибирск, просп. Академика Коптюга, 3, Россия

e-mail: pol@igm.nsc.ru

(iD) https://orcid.org/0000-0003-2760-0754

\section{Сергей Анатольевич Каргополов}

канд. геол.-мин. наук, н.с.

Институт геологии и минералогии им. В.С. Соболева СО РАН 630090, Новосибирск, просп. Академика Коптюга, 3, Россия

Новосибирский национальный исследовательский государственный университет

630090, Новосибирск, ул. Пирогова, 2, Россия

e-mail: kargo@igm.nsc.ru

\section{Андрей Эмильевич Изох}

докт. геол.-мин. наук, профессор

Институт геологии и минералогии им. В.С. Соболева СО РАН 630090, Новосибирск, просп. Академика Коптюга, 3, Россия

Новосибирский национальный исследовательский государственный университет

630090, Новосибирск, ул. Пирогова, 2, Россия

e-mail: izokh@igm.nsc.ru
Oleg P. Polyansky

Doctor of Geology and Mineralogy, Head of Laboratory

V.S. Sobolev Institute of Geology and Mineralogy, Siberian Branch of RAS

3 Academician Koptyug ave, Novosibirsk 630090, Russia

Sergei A. Kargopolov

Candidate of Geology and Mineralogy, Researcher

V.S. Sobolev Institute of Geology and Mineralogy, Siberian Branch of RAS 3 Academician Koptyug ave, Novosibirsk 630090, Russia

Novosibirsk State University

2 Pirogov street, Novosibirsk 630090, Russia

\section{Andrei E. Izokh}

Doctor of Geology and Mineralogy, Professor

V.S. Sobolev Institute of Geology and Mineralogy, Siberian Branch of RAS 3 Academician Koptyug ave, Novosibirsk 630090, Russia

Novosibirsk State University

2 Pirogov street, Novosibirsk 630090, Russia 


\section{Александр Николаевич Семенов}

\section{аспирант}

Институт геологии и минералогии им. В.С. Соболева СО РАН 630090, Новосибирск, просп. Академика Коптюга, 3, Россия

\e-mail: semenov@igm.nsc.ru

(iD) https://orcid.org/0000-0001-9732-5749

\section{Алексей Владимирович Бабичев}

канд. физ.-мат. наук, с.н.с.

Институт геологии и минералогии им. В.С. Соболева СО РАН 630090, Новосибирск, просп. Академика Коптюга, 3, Россия

e-mail: babichev@igm.nsc.ru

\section{Александр Николаевич Василевский}

H.C.

Институт нефтегазовой геологии и геофизики им. А.А. Трофимука СО РАН

630090, Новосибирск, пр. Академика Коптюга, 3, Россия

Новосибирский национальный исследовательский государственный университет

630090, Новосибирск, ул. Пирогова, 2, Россия

e-mail: VasilevskiyAN@ipgg.sbras.ru

(iD) https://orcid.org/0000-0002-8732-6198

\section{Aleksander N. Semenov}

Post Graduate Student

V.S. Sobolev Institute of Geology and Mineralogy, Siberian Branch of RAS 3 Academician Koptyug ave, Novosibirsk 630090, Russia

\section{Aleksei V. Babichev}

Candidate of Physics and Mathematics, Senior Researcher

V.S. Sobolev Institute of Geology and Mineralogy, Siberian Branch of RAS 3 Academician Koptyug ave, Novosibirsk 630090, Russia

\section{Aleksander N. Vasilevsky}

Researcher

A.A. Trofimuk Institute of Petroleum Geology and Geophysics, Siberian Branch of RAS

3 Academician Koptug ave., Novosibirsk 630090, Russia

Novosibirsk State University

2 Pirogov street, Novosibirsk 630090, Russia 